recent refugees from various African countries. Olga later co-founded a non-profit organization called African Community Education program. This program's mission is to bring the community together and start a Saturday school for the children where African adults serve as teachers, tutors and volunteers, working alongside non-African teachers and tutors in Worcester.

As president of the International Health Interest Group (IHIG) during her second year of medical school, Olga developed and organized an international service project in La Romana, Dominican Republic. This service project is now an annual spring break trip for dozens of medical students, nursing students and faculty. Olga took an extra year of medical school to develop a portable paper medical record-keeping system for each patient of the bateyes-villages on sugarcane plantations. Olga has received a scholarship, multiple grants and travel awards to help fund her ongoing work in La Romana.

Olga's experiences with so many diverse people and cultures have humbled her and taught her to see each person first and foremost as an individual. As a family physician, Olga hopes to be able to provide the best quality care to patients from all over the world.

Jane Ireland

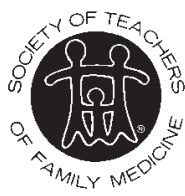

From the Society of Teachers of Family Medicine

Ann Fam Med 2009;7:89-90. DOI: 10.1370/afm.957

\section{STFM FOCUSES ACTIVITIES ON THE PATIENT-CENTERED MEDICAL HOME}

The Society of Teachers of Family Medicine has been focusing many of its efforts on the development of discipline-wide activities furthering the patient-centered medical home.

1) Clerksbip Medical Home Initiative: At its January 2008 Board meeting, the STFM Board approved a proposal to fund a 2-year observational study of the development of medical home teaching clinical experiences for family medicine clerkship students. The goal of the project is to understand efforts to spread the patient-centered medical home $(\mathrm{PCMH})$ model to clerkship teaching practices. Family medicine needs to learn more about the current status of clerkship clinical practice sites and the extent to which they teach the PCMH model.

This study is being conducted under the supervision of the STFM Research Committee by investigators at Oregon Health \& Sciences University who are also conducting the $\mathrm{P}^{4}$ evaluation. OHSU will evaluate 13 medical schools and their preceptors for this project We expect to be collecting data from each site this fall.

2) Joint Project with SGIM and APA: STFM is collaborating with the Society of General Internal Medicine and the Academic Pediatrics Association on a project designed to create a research agenda for the PCMH. The project includes holding a national conference on the PCMH looking at the evidence regarding the PCMH, what we currently know, what we need to know, and how to advance and disseminate this knowledge base.

The current scope includes 1 main conference and other meetings:

1. The main conference, which will be an invited conference for approximately 100 participants. This is tentatively planned for mid-2009.

2. A planning meeting for this main conference was held on October 7, 2008, in Washington, DC. At the planning meeting the several themes emerged. The steering committee is currently working to prioritize these themes. White papers will be commissioned on these themes and these will serve as discussion points for the main conference.

3. A demonstration project conference was held December 2, 2008. This was an invited conference, where researchers who have done demonstration project evaluations presented their findings.

The steering committee of the main conference includes representatives from the 3 primary care specialties as well as research, government and private industry.

3) STFM Group on the PCMH: STFM Board approved a new STFM Group on the Patient-Centered Medical Home, chaired by John Rogers, MD, MPH, MEd, and Caryl Heaton, DO. This group will serve as a key resource within STFM for furthering the work to establish the PCMH within teaching sites. The group has set a goal of developing and serving as a communications forum for discussion, problem solving, and teaching around the medical home

4) New Training for the PCMH Worksbop: STFM offered a new faculty development offering cosponsored by the University of South Carolina. "Training for the Patientcentered Medical Home: Integrating Practice Redesign Into the Residency Curriculum," was held October 25, 2008, in Columbia, South Carolina. Libby Baxley put together a strong team that guided the development of this workshop. Over 40 individuals attended.

5) STFM/AAFP Conference on Practice Improvement was held December 4-7, 2008, in Savannah, Georgia. The conference theme was, "Blueprint for the Medical Home" and the conference offered the practical skills, information, and resources enabling attendees to create the patient-centered medical home in their offices. 
We also be partnered with TransforMed to offer a 4-hour preconference session at the conference, Conference on Practice Improvement Learning Collaborative: A Partnership with TransforMED. This session provided a face-to-face networking opportunity for practices that wanted to learn more about the TransforMED PCMH model. This program will also provide ongoing communication between participants and will provide the opportunity for coaching from TransforMED facilitators. Participants were exposed to the collaborative learning style which, when combined with the experience, tools, and expertise of the TransforMED facilitators, provided the foundation for maintaining the success of the TransforMED NDP. This new program offered a jump-start on the TransforMED process and provided resources for making the needed changes within a practice.

Those attending this session learned to:

1. Identify the elements of a PCMH

2. Articulate the importance of the foundational components of leadership, teamwork, and communication to the development, ongoing implementation, and successful transition to the medical home practice

3. Communicate a basic understanding of the requirements for practice recognition as a $\mathrm{PCMH}$

4. Create an understanding of the integrated care management process

5. Formulate a plan for assessing the practice's current stage of medical home readiness and develop a plan for further implementation of the elements of the model

A follow-up program will be offered at the 2009 STFM Annual Meeting in Denver.

6) Competency Curriculum Modules: Four competencybased curriculum modules related to the PCMH are posted on STFM's Family Medicine Digital Resources Library (http://www.fmdrl.org), and we're beginning to share information on these materials in our publications. ADFM has shared these links on its listserve, along with favorable reviews of the materials. Our Group on Evidence-based Medicine is working on a new module.

- Competency-based Curriculum: Group Visits

- Competency-based Curriculum: Chronic Care Model

- Competency-based Curriculum: Quality Improvement

- Competency-based Curriculum: Advance Access 7) Otber PCMH Activities:

- The PCMH has been or will be the conference theme for our major conferences, including the 2009 annual meeting with the theme, "Transforming Education to Meet the Needs of the Personal Medical Home." We'll feature a PCMH track as part of the 2009 annual meeting offerings.
- We have published several articles in Family Medicine (including 7 president's columns by John Rogers, which are available as a set on FMDRL) and the STFM Messenger.

- In addition to the competency curriculum modules, there are other documents on FMDRL that relate to the $\mathrm{PCMH}$.

- The STFM Education Committee is putting together a matrix of resources to assist members' practices in becoming PCMHs.

- STFM participates in the Council of Academic Family Medicine, which has a subcommittee focused on the PCMH. This subcommittee is looking at opportunities to incorporate mental health into the PCMH. They are also looking at ways to collect information on $\mathrm{PCMH}$ adoption in residency education.

Jobn Rogers, MD, MPH, Med

Caryl Heaton, DO

Chairs, STFM Group on the Patient-centered Medical Home

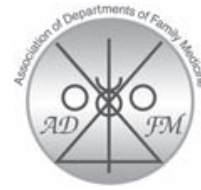

From the Association

of Departments of Family Medicine

Ann Fam Med 2009;7:90-91. DOI: 10.1370/afm.953.

\section{ADVANCED ACCESS IN ACADEMIC SETTINGS: DEFINITIONAL CHALLENGES}

Enhanced access to care is a hallmark of the patientcentered medical home. The first standard in National Committee for Quality Assurance (NCQA) criteria for certification as a medical home requires that practices have written standards for patient access and communication, and that they use data to show they meet these standards. Methods by which practices may do so include open scheduling, expanded hours, and new options for communication between patients, their personal physician, and practice staff.

One solution for reducing delays for appointments is advanced access scheduling — strictly defined as offering each patient an appointment with their preferred clinician at the time of their choice-which is touted as a way for ambulatory practices to improve both access and continuity. Many community practices have experienced success with this scheduling model by demonstrating increased appointment availability, increased patient satisfaction, decreased no-show rates, and increased revenues.

Within academic practices, delayed access is exacerbated by faculty and residents who are only part-time within their continuity practices, day-to-day variation 